\title{
NorDiNa 3(1): a continuing success story!
}

We are happy to present to you a new issue of NorDiNa, entitled 3(1). In our editor heads, it is thought of as "No 6", but we have, due to pressure from library systems and the like, chosen to change our numbering system to the more common Volume-Issue system.

Apart from library systems, responses to NorDiNa have been highly positive the two years it has been around. In fact, voices from Norwegian Ministry of Education (Kunnskapsdepartementet) have spoken of NorDiNa as a "success story" in their review of journals that are to be accredited as medias for scientific production. Why this success? We have experienced that NorDiNa fulfils a real need in that we have a steady stream of incoming manuscripts. Researchers in science education seem to acknowledge the possibility of publishing on a scientific level to a Nordic audience, which means reaching beyond the national sphere, but still being able to include contextual issues often lost when publishing internationally and - for some of us - to write scientifically in our own language. In particular we appreciate to see a growing number of NorDiNa articles included in thesises of $\mathrm{PhD}$ candidates in science education.

At times NorDiNa could need even more manuscripts, yet we quite often find ourselves rather close to the limit of what amount we are able to handle as editors. This is of course due to the low number of people involved in the main work. On the other hand, this is also what enables us to work at a very high efficiency, which we believe forms part of the success our journal has achieved. In this work we are dependent of a growing network of referees, who contribute with often very constructive evaluation of manuscripts. Our direct contact with our referees ensures the efficiency and commitment on both sides.

We believe that the balance NorDiNa this way has found between being professional and being "home-made" (quite often the latter is true in a literary sense) is the most important aspect of its success. It is important to note that this could not have been realised without the economic, practical and technical support from the Norwegian Centre for Science Education (Naturfagsenteret), and especially the skills and goodwill of Lise Faafeng who performs all the technical work for us with loads of patience and commitment.

Our field of research comprises a variety of themes and research approaches. The articles we present in the current and previous issue of NorDiNa reflect some of this variety. One important strand of research is the one dealing with teachers; how they develop in their training, how they perceive the purpose and potential of ways of working in science teaching, such as laboratory work and out-door education. This strand is represented by the articles (in the previous issue) How teachers' understanding of the greenhouse effect develops during a teacher education programme (Margareta Ekborg \& Mats Areskoug), Lärares mål med laborativt arbete: Utveckla förståelse och interesse (Per Högström, Christina Ottander \& Sylvia Benckert) and Reading Nature - experienced teachers' reflections on a teaching sequence in ecology: implications for future teacher training (Ola Magntorn and Gustav Helldén). The research presented in these articles shows us that the work of science teachers is a complex matter to perform as well as to understand, and that we meet many challenges as science educators. 
The last article mentioned above makes a metaphorical link between observing and understanding nature and the concepts of reading and literacy. This brings us to a second strand of current research focus represented in NorDiNa and elsewhere; the one related to language and its importance for learning in science. In his article in the previous issue, Carl-Johan Rundgren gives an empirical and theoretical contribution to this field in analysing how the use of an intermediate language, in terms of metaphors and helpwords contributes to meaning making in learning science.

The explanation of phenomena is important in science and hence an important area of research in science education. In his article in the previous issue, Harry Silfverberg investigates how primary school pupils explain the disappearance of rays of light, and reports six different categories of explanations, again in terms of metaphors. Pupils' understanding of phenomena is also investigated in a longitudinal study by Ann-Charlotte Lindner and Andreas Redfors (this issue). In their article they show how the concept of matter as particles effects learners' explanation of evaporation.

Some disciplines within science, such as physics, are to a great extent expressed in terms of mathematical equations. 'Understanding physics' is hence related to 'understanding equations'. What this means to students is explored by Daniel Domert, John Airey, Rebecca Kung and Cedric Linder in their article An exploration of university students' epistemological mindsets towards the understanding of physics equations (this issue). Learning within physics is also investigated by Åke Ingerman, Cedric Linder, Delia Marshall and Shirley Booth in their article Learning and the variation in focus among physics students when using a computer simulation (this issue). They identify various focuses among students when using computer simulations in physics, and discuss how these may affect learning outcomes.

The last group of research studies we identify in these to issues of NorDiNa is the one embracing attitudes, interest, motivation and learning strategies. Rie Popp Troelsen gives an analysis of what the concept of interest means and presents results from life history interviews in her article in the previous issue (Interesse og interesse for naturfag). She here demonstrates how the concepts of interest may be understood in different ways. While the articles presented above are to a great extent qualitative and reflective, two articles in the present issue report quantitative studies. Tom Klepaker, Siv Flæsen Almendingen and Johannes Tveita investigate how the use of "student-active teaching practice" relates to learning outcome and students' attitude to science. They verify that different teaching practices significantly influence students' attitudes to science and their science teacher. Gender differences is the focus in the study reported by Eyvind Elstad and Are Turmo, where they analyse students' self-reported motivation, use of learning strategies and self-regulation in science. They conclude that there are significant gender differences in many respects.

Besides these articles, we present book chapters by Stein Dankert Kolstø (previous issue) and Marianne Ødegaard (this issue), and continue to print abstracts of dissertations and descriptions of projects. In this issue the latter includes a description of the project FYS21 (by Carl Angell, Ellen K. Henriksen and per Morten Kind) and a report on the ongoing work with planning the $9^{\text {th }}$ Nordic Research Symposium in Science Education, taking place in Reykjavik June 2008. Before gathering there, we look forward to see many of you for the ESERA conference in Malmö this summer!

Editorial greetings,

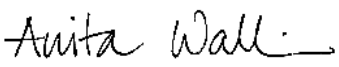

Anita Wallin

Göteborgs universitet

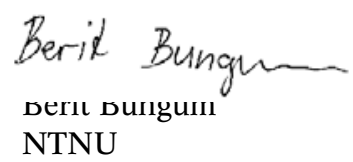

NTNU

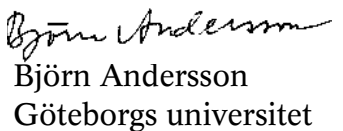

